\title{
ATITUDES LINGUÍSTICAS DE TRABALHADORES DE CIUDAD DEL ESTE QUANTO AO JOPARÁ NO JORNAL DIARIO POPULAR
}

DOI: $0.48075 / R I . V 22 I 2.25306$

Luciano Marcos dos Santos ${ }^{1}$

RESUMO: No presente estudo, apresento reflexões referentes às atitudes linguísticas de paraguaios, trabalhadores do comércio de Ciudad del Este, quanto ao jopará, variação caracterizada pelo contato entre as línguas guarani e castelhano, nas páginas policiais do periódico Diario Popular, correlacionadas às ações de gestão sobre as línguas, ocorridas neste ambiente linguístico. Para tanto, reanaliso dados provenientes de outras incursões sobre o tema, os quais, sob a perspectiva em foco, permitiram-me entender a relação entre as ações de planejamento linguístico no Paraguai, pautadas pelo poder exercido pelas classes dominantes, cuja ideologia é propensa à homogeneização cultural e ao prestígio das línguas oficiais, guarani e castelhano, e a formação de conceitos que aceitam e limitam o jopará a espaços de uso da linguagem informal. Os dados são provenientes de uma sondagem sobre o uso do jopará pelos órgãos de imprensa paraguaios, da análise de 151 exemplares do Diario Popular e da aplicação de 50 questionários aos trabalhadores da zona de comércio de Ciudad del Este, leitores do jornal. O presente estudo, de caráter qualitativo, cujos resultados compreendem a realidade de maneira parcial, oferece um panorama sobre as questões linguísticas paraguaias.

Palavras-chave: Atitudes Linguísticas; Jopará; Diario Popular.

\section{LANGUAGE ATTITUDES OF WORKERS FROM CIUDAD DEL ESTE TOWARDS TO JOPARÁ IN THE NEWSPAPER DIARIO POPULAR}

ABSTRAC: The current study presents some reflections from the linguistic attitudes of Paraguayans, trade workers in Ciudad del Este towards to jopará, a variation characterized by contact between the Guaraní and Castellano, in the police pages of the newspaper Diario Popular, correlated to management actions on languages, occurred in this linguistic environment. For this purpose, I reanalyze data from other incursions on the subject, which, from the perspective in focus, have allowed me to understand the relationship between linguistic planning actions in Paraguay, guided by the power exercised by the dominant classes, whose ideology is prone to the prestige of the official languages, guarani and castelhano, which tend to accept and limit jopará to spaces of informal language use. The data comes from a survey about the use of jopará by Paraguayan press organs, the analysis of 151 copies of Diario Popular, and the application of 50 questionnaires to workers from trade of Ciudad del Este, readers of the newspaper. The present study, of a qualitative nature, which the results understand the reality in a partial way, intends to offer another panorama for the linguistic question in Paraguay.

\footnotetext{
${ }^{1}$ Mestre e doutor em Sociedade, Cultura e Fronteiras (UNIOESTE). Professor de língua portuguesa e espanhola do Instituto Federal do Paraná (IFPR), Foz do Iguaçu, Paraná. E-mail: luciano.santos@ifpr.edu.br
} 
Key Words: Linguistic Attitudes; Jopará; Diario Popular.

\section{INTRODUÇÃO}

Decorrente de sua constituição histórica e social, o Paraguai se configura como um país de formação cultural mestiça, marcada pelo contato de duas sociedades: cristãos espanhóis e Guarani. No terreno sociolinguístico, o país se caracteriza pela predominância de indivíduos bilíngues e pela circulação das línguas/variações: castelhano, guarani, jopará (grafia em português), entre outras. As duas primeiras são identificadas como línguas dominantes, decorrente de fatores históricos e políticas linguísticas expressas em forma de leis constitucionais que reconhecem o guarani como língua nacional (Constituição de 1967); que confirmam o Paraguai como nação bilíngue e o guarani e o castelhano como línguas oficiais, assim como, determina o ensino obrigatório de guarani pelo sistema educacional (Constituição de 1992).

Tais ações, dentre outras, alçaram o guarani e o castelhano a símbolos nacionais, impulsionando suas legitimações, reflexo da valorização das línguas "puras" e da imposição à homogeneidade cultural no processo de construção da identidade nacional.

Quanto ao jopará, de tradição oral, não normatizado, expressão da hibridez cultural (língua castelhana e guarani), presente no cotidiano da população, no ambiente linguístico ${ }^{2}$ paraguaio, pelos fatores apresentados, pelo compartilhamento de crenças e reflexo de intervenções do Estado na gestão das línguas, pode ter seu uso interconectado a um processo que o marginaliza e o limita a espaços de uso não protocolares.

Entender a presença do jopará, unicamente em jornais populares paraguaios, tais como o Diario Popular (grafia em castelhano), foi uma questão que norteou outras investigações realizadas, das quais obtive dados que confirmaram algumas constatações e revelaram alguns conceitos e atitudes quanto ao tema, que me propiciaram analisar tal problemática sob outros olhares.

O Diario Popular é um jornal de circulação nacional, com sede na capital, Assunção. Sua grande vendagem se deve, além de outros fatores, ao seu valor acessível. Segue os padrões

\footnotetext{
2 Segundo Calvet (2007), trata-se da limitação de circulação de algumas línguas ou variações na vida cotidiana de certas comunidades.
} 
Dossiê: Atitudes Linguísticas e Políticas Linguísticas: abordagens interdisciplinares

gráficos e editoriais dos tabloides. Pude verificar, na região de comércio popular de Ciudad del Este, no Paraguai, a constante leitura desse jornal, daí meu interesse por este assunto, além de minha atuação enquanto professor de espanhol em Foz do Iguaçu, cidade que faz fronteira com Ciudad del Este.

A dúvida sobre o que pensavam os paraguaios, leitores do Popular, trabalhadores do comércio, quanto ao jopará no jornal, foi propulsora e norteadora do presente estudo. A hipótese, segundo o referencial consultado, é que as atitudes linguísticas dos funcionários do comércio de Ciudad del Este diante do jopará no Diario Popular estão interconectadas às ações do Estado, concernentes à gestão sobre as línguas no Paraguai e à aceitação de sua circulação restrita aos contextos informais de uso.

Com essa perspectiva, o presente artigo apresenta reflexões referentes às atitudes linguísticas de paraguaios, trabalhadores do comércio de Ciudad del Este quanto ao jopará no jornal Diario Popular. Para tanto, esta investigação compreende a temática em questão, segundo alguns aspectos indissociáveis: 1) o ambiente de contato linguístico, envolto em relações sociais, que são relações de força; 2) a intervenção do Estado, de grupos detentores de poder, na gestão das línguas; 3) desenvolvimento de crenças e atitudes linguísticas dos leitores do jornal, comerciantes de Ciudad del Este, Paraguai.

Para a elaboração deste estudo, recorri aos dados coletados, decorrentes das pesquisas realizadas entre 2011 e 2019, que trataram sobre o assunto em foco, cujas abordagens foram de caráter qualitativo, portanto a realidade foi apreendida de forma parcial.

Para compreender a incidência de uso do jopará em jornais populares paraguaios, com ênfase em notícias de tema policial, empreguei como procedimento metodológico a análise documental, pela qual, por meio da sondagem dos órgãos de imprensa do Paraguai, foi selecionado o Diario Popular, devido ao seu grande alcance dentre os populares que exclusivamente empregavam o jopará na redação de suas matérias. Por meio de um levantamento quantitativo, foram analisados 151 exemplares físicos do Popular, correspondentes aos meses de janeiro a maio de 2011.

Para constatar a concentração do emprego do jopará na seção que registra crimes, uma planilha foi criada, organizada por cadernos do jornal e todos os vocábulos de origem guarani, em língua jopará, foram transcritos. Ao final, de maneira matemática, apurei que mais da metade das mais de vinte mail palavras encontradas reuniam-se no caderno que registra as 
ocorrências policiais.

Outro procedimento que lancei mão para apurar o que os trabalhadores do comércio de Ciudad del Este pensavam sobre o tema em evidência, foi a elaboração e aplicação de um questionário a cinquenta respondentes. Para os propósitos do presente estudo, quanto a esse instrumento, de um total de nove questões, foram selecionados os dados percentuais provenientes de três inquirições objetivas e as respostas escritas procedentes de uma questão aberta, que averiguaram de forma subjetiva, os juízos quanto ao jopará no contexto em foco, conforme o quadro:

Quadro 1-Questões de pesquisa

\begin{tabular}{|l|l|}
\hline Questão fechada 1 & Qual sua opinião sobre o jopará no Diario Popular? \\
\hline Questão fechada 2 & O Diario Popular deveria ter matérias escritas somente em castelhano? \\
\hline Questão fechada 3 & O Diario Popular deveria ter matérias escritas somente em guarani? \\
\hline Questão aberta & O que você sente quanto às palavras de origem guarani na seção criminal? \\
\hline
\end{tabular}
Fonte: (Elaborado pelo autor; SANTOS, 2019)

Para os objetivos que me proponho, respaldo-me no escopo da Política Linguística (CALVET, 2007) e das Atitudes Linguísticas (AGUILERA, 2008; GARRETT, 2020; MORENO FERNÁNDEZ, 1998, entre outros).

Tendo em vista o contexto analisado, em que as tomadas de ações relativas às línguas, que conformam as políticas linguísticas, perpassam o espaço social, engendradas ao poder, embaso-me nos estudos de Pierre Bourdieu para compreender que as relações entre língua e sociedade são relações de força (BOURDIEU, 1996; 2009; 2014).

Os discursos em torno do jopará são controversos, o que amplia as argumentações quanto aos seus significados. Fio-me, segundo a perspectiva adotada neste estudo, às pesquisas de Zajícová (2009), que define esse fenômeno como um continuum caracterizado pela variação entre os níveis de contato do guarani e do castelhano, quanto aos aspectos fonéticos e morfológicos.

Kallfell (2016) corrobora, ao afirmar que o entrelaçamento das línguas não decorre uma variedade estável, havendo, dessa maneira, diferentes formas do jopará. $\quad$ Para $\quad$ o presente trabalho, considero o jopará enquanto linguagem coloquial escrita, presente em um jornal popular, em que o castelhano é a base, língua dominante, intercalada por expressões em língua guarani (ZAJíCOVÁ, 2009, p. 29). 
Os resultados obtidos, mesmo que de forma parcial, ajudam a compreender o ambiente linguístico paraguaio e pretendem contribuir às pesquisas destinadas a esta temática.

\section{A PRESENÇA DO JOPARÁ NO DIARIO POPULAR}

O Paraguai se distingue de outros países da América do Sul por ter uma língua indígena como oficial. Esse fato desperta interesse, especialmente em linguistas desejosos em entender que fatores levaram à conservação do guarani até os dias atuais, assim como, apresenta peculiaridades, especialmente por estar conectado a uma série de ações imbricadas em políticas linguísticas, as quais atenderam a interesses diversos.

Tais políticas me interessam, visto que, para analisar a presença do jopará no Diario Popular, segundo princípios sociolinguísticos, com o foco pretendido, é necessário conhecer os fatos que garantiram a não extinção da língua guarani e seu trajeto até alcançar o status de língua oficial, enfrentando, contudo, nesse caminho, em virtude dos desdobramentos dos aspectos citados, que atingiram as relações dos sujeitos com as línguas, conceitos que o atrelam, até a atualidade, aos estigmas: língua de índio, bárbaro, atrasado, língua da pobreza. Realizo a incursão nesta trajetória, inicialmente.

Associada a esse itinerário, está a forma crítica como me posiciono. Ciente que as línguas empregadas no Paraguai não apresentam uma unidade e que a cultura manifesta em seus símbolos o contato entre Guarani e espanhóis, argumento em função da desconstrução do mito das línguas "puras" que ocorre na sociedade paraguaia. Resguardo-me nos estudos de Melià (1992), entre outros, que apontam para a não existência de guarani ou castelhano, desde o período colonial, sem graus de intercessão de uma língua na outra. Entendo que existe no país a valorização das línguas oficiais por parte de uma minoria social, detentora de poder, com respeito às suas (relativas) regularidades linguísticas, com preponderante valor atribuído ao castelhano (CORVALÁN, 1993).

Sequencialmente, defino o jopará com base na Sociolinguística, para então, com apoio nos dados de que disponho, analisar seu uso no contexto em foco e constatar seus reflexos, cujos resultados apontam para a inter-relação entre o planejamento linguístico e a formação de atitudes linguísticas. Iniciamos pelo caso da língua guarani. 
Ao longo de sua história, o guarani paraguaio sofreu alterações, mas aqui cabe salientar que se trata de uma língua derivada do guarani autóctone, com vários graus de espanização. Curiosamente, segundo Melià (1998), os originários falantes da língua guarani, povos indígenas do tronco tupi-guarani, não sobreviveram ao seu próprio idioma. Os poucos núcleos de população indígena restantes, na atualidade, utilizam uma variação da língua, majoritariamente em contexto oral, familiar e informal.

Melià (1998) aponta para a exclusividade de uso da língua castelhana pelos membros que formavam a sociedade colonial, não havendo espaço para a língua guarani, nem na administração e nem na política, o que se pronunciava como forma de controle e dominação, devido a condicionar os falantes de guarani ao pouco acesso a tudo que compunha o mundo hispânico, especialmente sua língua materna. Contudo, observa que houve certa valorização do guarani pelos jesuítas, confirmada pela escrita de muitas obras nessa língua, uma vez que viam nela resquícios de um sentimento divino mais primitivo e não uma forma de expressão selvagem.

Conforme Meliá (1992), os jesuítas proporcionaram, por meio de ações sobre o guarani, uma base importante para a conservação da língua até a atualidade. Dentre estas ações, estava o emprego exclusivo de língua "pagã" na evangelização, o que demandava estudo do guarani tribal, cuja intenção era o estabelecimento e manutenção da unidade e do controle, promovidos, também, pelo isolamento estabelecido nas Reduções, o que minimizou qualquer incursão de grupos invasores, tais como os bandeirantes. Essas interações não eram realizadas unicamente em guarani tribal, mas sim, sucediam de maneira mesclada, guarani e castelhano, algo que aconteceu também no sistema colonial, como forma de potencializar a comunicação.

Segundo Melià (1997), tendo em vista o poderio espanhol, a política linguística da coroa foi calcada no estabelecimento efetivo da língua castelhana, o que compreendia toda maneira de expressão em situação formal, contudo a imigração no Paraguai foi relativamente fraca, permanecendo o país indígena, demograficamente e linguisticamente. Os Guarani, cujo sistema de comunicação atendia suas necessidades, passaram a expressar-se constantemente em sua língua, que gradativamente apresentou graus de contato acentuado de castelhano.

A formação social, cultural e linguística paraguaia, caracterizada como arbitrária e conflitante, espelha os embates nestes terrenos, em que a elite econômica e cultural, apesar de demograficamente inferior, impôs, perpetuou e legitimou seus hábitos, suas crenças, 
costumes, sua língua. Segundo Méndez (2013), em torno do espectro da língua guarani, no Paraguai, pairam avaliações que a conectam ao símbolo do arcaísmo e seu uso representa um retardamento frente ao mundo moderno e globalizado.

Percebe-se que apesar de conservado, o uso do guarani é ainda atrelado ao estereótipo: língua da pobreza. Umas das causas dessa estigmatização, além de remanescente do período colonial, caracterizado pelo domínio das expressões da cultura europeia, advêm da instabilidade política e brutal desigualdade social que imperam em muitos países da América do Sul, frutos de políticas sociais estruturadas em relações desiguais, que visaram favorecer uma pequena parcela da população que se define como falante de castelhano, detentora de poder econômico e consequentemente simbólico.

No Paraguai, isso se observa em fatos históricos, tais como a centralização de poder durante o governo do ditador Gaspar Rodríguez de Francia (1814-1840), que adotou o isolamento do país como forma de defesa do Estado contra inimigos, o que, segundo Chiavenato (1979), acarretou em problemas econômicos que afetaram a idealizada progressão educacional e bloquearam a aprendizagem e expansão, em termos linguísticos, do castelhano monolíngue, língua atrelada à prosperidade social.

Portanto, o fracasso e "atraso" do país, relativos às questões levantadas, atingem a população e se refletem nos elementos da cultura, tais como os conceitos em relação às línguas, calcados em discursos que acercam o êxito econômico e social à implantação efetiva do castelhano "puro" em lugar do guarani, falado pela grande maioria da população (CORVALÁN, 1993).

Contudo, no período das guerras da Tríplice Aliança e do Chaco, a língua guarani foi importante para os propósitos bélicos e qualificada como símbolo da defesa da nação, uma vez que seu uso estimulava o sentimento de orgulho de ser paraguaio. Visando ampliar resultados, os paraguaios contavam com a língua como aliada em suas táticas de guerra e para a restrição das informações, pois os outros povos envolvidos nos conflitos não dominavam este idioma.

Lustig (2017) ressalva que, em decorrência da guerra, apesar de todas as perdas, em múltiplos terrenos, em termos linguísticos, levando-se em conta as línguas em contato, o guarani padronizado fortaleceu-se e se tornou símbolo de orgulho nacional, associando o sentimento de ser paraguaio à possibilidade de expressar-se em guarani. 
Dossiê: Atitudes Linguísticas e Políticas Linguísticas: abordagens interdisciplinares

O valor emotivo, segundo Rodríguez Zuccolillo (2000), que o guarani desperta na população paraguaia, está relacionado, além de questões pátrias, à memória afetiva construída e sustentada por seus defensores, pertencentes à elite cultural, que manifestam sentimentos de lealdade à variação "pura" da língua, idealizada.

O status que o guarani "puro" alcançou junto à elite cultural paraguaia é proveniente da prática espontânea da língua, dos fatores já apresentados, mas também fruto da ação in vitro, a qual, segundo Calvet (2007), compreende o planejamento linguístico. Dentre estas ações, está a criação de leis.

Durante o governo de Alfredo Stroessner (Constituição de 1967), o guarani passa a ser língua nacional, embora fosse mantido o castelhano como única língua oficial

Em 1992, a nova Constituição, pós-stronista, afirmou a condição do Paraguai como nação bilíngue, estabelecendo o guarani e o castelhano como línguas oficiais e determinando a obrigatoriedade do ensino em língua materna.

Em 29 de dezembro de 2010, outra grande decisão com respeito às línguas no Paraguai foi a promulgação da Lei 4251, que legislava em função da regulamentação dos idiomas oficiais. Decorrente desta lei, foi criada a Secretaria de Políticas Linguísticas e a Academia da Língua Guarani, responsáveis pela elaboração da normalização e estandardização do guarani. A criação de tais leis teve como meta a difusão do guarani padrão, contudo a realidade, em termos acadêmicos e sociais, é outra.

Segundo Krivoshein de Canese (1996), a língua mais falada pela população, caracterizada pelo guarani ou castelhano com graus de contato acentuados, não é aceita na educação. Segundo Corvalán (1993), a exigência é a competência linguística em guarani e castelhano padrão, sem “interferências", porém, sobretudo quanto ao ensino de língua guarani, seja por problemas de má formação acadêmica, ou por problemas sociais, converte-se em uma árdua tarefa, tornando-se o guarani acadêmico ("puro"), uma língua externa e inalcançável. Patiño (2013); Gasparín (2016) corroboram com esta tese, ao observarem que o sistema escolar, assim como toda atividade da vida social paraguaia que expressa oficialidade, ignora a realidade sociolinguística da população.

E quanto ao jopará?

As definições e argumentações em torno da língua jopará são amplas e se tornam controversas. Para classificar este fenômeno social e linguístico, segundo meus objetivos, fio- 
me aos estudos de Zajícová (2009), que apontam diferentes formas (uso, circulação e composição) do jopará, corroborando com a ideia de que ele existe desde a época colonial. As missões dos jesuítas exigiam traslados entre os povos e vilas, dessa atividade provem relatos, cujos olhares críticos observavam a existência de um guarani diferente do "jesuítico", considerado como adulteração e já fortemente interpenetrado pelo castelhano.

Esta autora, baseada em diferentes pontos de vista, pondera sobre o jopará:

El guaraní influido por el castellano ha recebido popularmente el nombre jopara, "mezcla, mezclado" en guaraní, que, sin embargo, es un término con el que los hablantes suelen referirse a fenómenos lin-güísticos muy heterogéneos, que, además, no se excluyen entre sí, es decir, se trata de un continuum no solamente a nivel de proporción de ambas lenguas, sino también a nivel de tipo del resultado del contacto lingüístico, desde los préstamos plenamente integrados fonética y morfológicamente, pasando por préstamos ocasionales, calcos, etc., hasta diferentes formas de la alternancia de código ${ }^{3}$. (ZAJíCOVÁ, 2009, p. 26)

A autora supracitada observa que se trata de uma variante do guarani tribal, cujos traços indicam diferentes formas de jopará, que serão empregados em diferentes contextos comunicativos, cuja constituição será formada a partir de recursos selecionados, não de uma das línguas, mas de maneira complementar, de ambas.

Com apoio no referencial teórico citado, constato que o jopará empregado nas redações jornalísticas do Diario Popular denota o baixo índice de material em língua guarani (somente 5\%). Trata-se do registro de uso coloquial, proposital, pautado na linguagem oral dos paraguaios, falantes do castelhano como língua dominante, em contextos informais ou familiares, que intercalam a esta língua basilar, expressões em guarani.

Kallfell (2016) aponta para a existência de tal fenômeno, datada de pelo menos 250 anos. Ele amplia o entendimento sobre o jopará do Diario Popular, uma vez que, segundo seus estudos relativos ao tema linguístico, de maneira geral, dependendo da localidade e do contexto, trata-se do entrelaçamento de duas línguas, que de forma mútua podem apresentar diferentes proporções, com frases estruturadas em guarani com empréstimos de léxico em

\footnotetext{
${ }^{3}$ O guarani influenciado pelo castelhano recebeu popularmente o nome de jopará, "mescla, mesclado" em guarani, que, no entanto, é um termo que os falantes costumam referir-se a fenômenos linguísticos muito heterogêneos, que, além disso, não se excluem entre si, quer dizer, se trata de um continuum não somente em nível de proporção de ambas línguas, mas também em nível de resultado de contato linguístico, desde os empréstimos plenamente integrados fonética e morfologicamente, passando por empréstimos ocasionais, transferências, etc., até diferentes formas de alternância de código. (ZAJícOVÁ, 2009, p.26 - tradução do autor).
} 
castelhano e o contrário, havendo predominância de falantes da primeira forma na região rural (cidades e vilas interioranas) e da segunda, estruturada em castelhano com empréstimos lexicais do guarani, em centros urbanos.

Como forma de comprovar as constatações, reemprego os dados provenientes ${ }^{4}$ de outras incursões sobre o tema. O primeiro dado trata da certificação que, do universo de veículos impressos que formam a imprensa paraguaia moderna, somente dois fizeram e fazem uso do jopará na redação de matérias: Diario Crónica e Diario Popular, os dois adequados ao estereótipo de jornal popular. O outro é decorrente da análise do Diario Popular, que revelou que do total de 151 exemplares sondados e 20.461 (vinte mil quatrocentos e sessenta e uma) palavras encontras, de origem guarani, em língua jopará, a grande maioria, 51\%, encontravase nos textos do caderno Sucesos - seção que registra as ocorrências policiais.

Dessa forma, o jopará empregado no Diario Popular e não o guarani ou castelhano "puros", sobretudo nas redações de matérias que formam a seção policial, segundo Amaral (2006), pode ser entendido, também, pelo fato de os jornais, pela linguagem, projetarem seu público, seus hábitos e gostos. No entanto, com base em outra visão, coadunada a essa, que ainda será aprofundada, segundo Calvet (2007), tal limitação pode ser reflexo da intervenção planejadora sobre o ambiente linguístico, conectada ao poder simbólico de grupos dominantes, cujos arranjos de ordem política, segundo o contexto analisado, podem refletirse no tácito acomodamento do jopará ao terreno da informalidade.

Jornais rotulados como sensacionalistas ou populares, como o Diario Popular, apresentam em sua configuração um espaço bastante grande, central, a temas relativos ao possível gosto do público leitor, os quais não escapam de serem noticiados nos jornais tidos como formais e "sérios", já que o tema da violência, por exemplo, é abordado em todos os veículos de comunicação.

Quanto à seção policial, ela expressa, de forma estereotipada, majoritariamente, o cotidiano de regiões carentes, em que são retratados "comportamentos desviantes". A distribuição dos fatos jornalísticos no jornal, em seus múltiplos cadernos, destinam outros espaços a outros personagens da sociedade, associados ao trabalho, à justiça e ao poder,

\footnotetext{
${ }^{4}$ Analisei a presença do jopará no Diario Popular sob a ótica sociológica, em que compreendo este tema como forma de distinção social. (SANTOS, 2012). Em outro estudo constatei que o jornal em questão emprega o jopará como maneira de construir sua imagem popular. (SANTOS, 2019) .
} 
Dossiê: Atitudes Linguísticas e Políticas Linguísticas: abordagens interdisciplinares

enfim, a uma ordem social legitimada. A seção criminal, ao designar-se a um setor especial, representa condutas sociais fora do padrão. (SERRA, 1980, p. 19).

Em jornais populares, ou rotulados como sensacionalistas, segundo Amaral (2006), ocorre a inversão da valorização do material jornalístico que compõe suas páginas. Desse modo, o que em um jornal "sério", seria tido como anomalia, resguardado à seção especial, em jornais populares é corriqueiro e abrangente, com destaque para as páginas policiais. Tudo que se refere ao estereótipo, do que seja o modo de viver, pensar, agir, expressar-se, de grupos sociais com pouco capital simbólico, espalha-se por esse tipo de noticioso.

O fato de jornais de referência, no Paraguai, empregarem massivamente o castelhano padrão, "puro", como forma de compatibilizar o conceito de jornalismo sério ao uso da linguagem de referência, que prima pelo "bom gosto" e polidez, acusa que as relações de interação, neste contexto, realizáveis por meio da língua e linguagem, são relações de força simbólica.

Bourdieu irá ressaltar os aspectos sociais relativos, não só aos bens culturais, como à materialização discursiva, os quais envolvem a produção de textos. Para ele, os "sistemas simbólicos" cumprem função política de impor, legitimar ou assegurar a dominação de uma classe sobre outra (violência simbólica); esta ação evidencia a existência de lutas no campo intelectual pelo monopólio da violência simbólica legítima (BOURDIEU, 1989, p. 10-12).

Sendo assim, com base nos dados apurados, quanto à questão do jopará em jornais populares, nas páginas policiais, observo que o processo de comunicação, que sintetiza a capacidade linguística aliada ao poder de engendramento, é, também, a adequação dos mesmos a um mercado ${ }^{5}$, que impõe sanções e censuras, já que, segundo Bourdieu (1996, p.24), as trocas linguísticas "são relações de interação humana e sociais, portanto são relações de dominação e poder simbólico, onde se atualizam as relações de força entre os locutores e seus grupos".

Tais constatações, conciliadas à perspectiva em foco, com base em Calvet (2007), permitem-me observar que a gestão das línguas (in vivo; in vitro) no Paraguai, seja pelo poder de grupos dominantes durante o período colonial, seja pela força e ação do Estado no período de guerras, pode ter influenciado a delimitação e aceitação do jopará, guarani e castelhano a

\footnotetext{
${ }^{5}$ Conforme Bourdieu (2009), essa noção de mercado está atrelada ao campo de produção de bens simbólicos, em que são reguladas as normas de produção e critérios de avaliação. Estes bens simbólicos concorrem pela legitimação cultural.
} 
Dossiê: Atitudes Linguísticas e Políticas Linguísticas: abordagens interdisciplinares

determinados espaços de circulação, assim como pode atuar na constituição de atitudes linguísticas de seus usuários.

Nessa ordem, observo que as políticas linguísticas são reflexos das ideologias de quem as criam e são capazes de trabalhar na formação de conceitos em relação ao que é certo e errado. Dessa forma, conhecer as políticas institucionalizadas no Paraguai é de extrema importância para entender que certos aspectos da realidade social são apagados, para que outros estejam em foco, ou seja, quanto ao campo linguístico, isto é perceptível por ações que levaram à valorização do castelhano, à oficialização do guarani e à marginalização do jopará.

Dessa maneira, no terreno da Sociolinguística, segundo Calvet (2007), o planejamento linguístico poderá interferir no ambiente, no peso das línguas e, consequentemente, na forma como os sujeitos agem com relação a elas e suas variações, como tratarei a seguir. 0 cerne, ressalvo, neste estudo, está no jopará no Diario Popular.

\section{A SOCIOLINGUÍSTICA E AS ATITUDES LINGUÍSTICAS}

Segundo o Censo Nacional de População e Habitação (2003), a distribuição linguística no Paraguai aponta que mais da metade (59\%) da população paraguaia se define como bilíngue, tendo o guarani como primeira língua. Em um ambiente, linguisticamente, socialmente e culturalmente tão adverso, as interações podem ser calcadas em relações de força e segundo essa configuração podem revelar tensões, conflitos, assentimentos e comportamentos.

Em um ambiente marcado por línguas em contato, os falantes constituem suas atitudes quanto a elas, decorrentes da avaliação que constroem quanto aos usuários, quanto à escolha de uma língua em detrimento de outra, de uma variante e não de outra e na maneira como sentem e reagem, de forma positiva ou negativa quanto a esses fatores.

Labov (1978), ao descrever uma variedade da língua inglesa falada por negros adolescentes do Harlen, em Nova lorque, verificou que as atitudes para com uma variante linguística não-padrão ultrapassavam o âmbito da linguagem e se estendiam ao âmbito dos falantes, usuários dessas línguas. Os estudos de natureza sociolinguística, tais como do autor citado, contribuem para o entendimento de questões referentes às línguas em contato.

Para Lopes (2001, p. 84), o objeto de estudo da Sociolinguística é a fala viva em seu 
Dossiê: Atitudes Linguísticas e Políticas Linguísticas: abordagens interdisciplinares

contexto real, não apenas a língua idealizada, objeto de outros tipos de estudo. Afirma, ainda, que a Sociolinguística é uma ciência que estuda fatos linguísticos propriamente ditos, em contextos sociais específicos, buscando descrever e interpretar as relações que tais fatos mantêm com o contexto social de sua produção.

Assim, a Sociolinguística preocupa-se em explicar a variabilidade linguística e sua relação com diversos fatores linguísticos e sociais, buscando, também, relacionar variação e mudança linguística. $O$ espaço de uso das línguas exige que haja um gerenciamento e intervenção, através da criação de estratégias ou ações de caráter político, bem como o comportamento dos usuários, em tais contextos, por meio de escolhas linguísticas, pode ser objeto de estudos.

Quanto ao comportamento, manifestado na forma de atitude, segundo a Sociolinguística, conforme os apontamentos de Moreno Fernández, define-se como:

[...] la actitud ante la lengua y su uso se convierte en especialmente atractiva cuando se aprecia en su justa magnitud el hecho de que las lenguas no son solo portadoras de unas formas y unos atributos lingüísticos determinados, sino que también son capaces de transmitir significados o connotaciones sociales, además de valores sentimentales. Las normas y marcas culturales de un grupo se transmiten o enfatizan por medio de la lengua. ${ }^{6}$ (MORENO FERNÁNDEZ, 1998, p. 178).

Tais conclusões estão apoiadas nos estudos inaugurais, concernentes à Psicologia Social. Lambert e Lambert (1966, p. 78), nessa esfera, pontuam que “[...] uma atitude é uma maneira organizada e coerente de pensar, sentir e reagir em relação a pessoas, grupos, questões sociais ou, mais genericamente, a qualquer acontecimento ocorrido em nosso meio circundante". É pertinente ressalvar que o conceito de atitude, neste estudo, está calcado em aspectos emocionais, particulares, influenciados pelo contexto e pelo meio social, assim como, entende-se que as crenças são um dos componentes da atitude. Nessa ordem, entendemos que as pessoas manifestam cotidianamente suas reações quanto às línguas, e muitas vezes não o fazem de maneira consciente (GARRETT, 2010).

\footnotetext{
${ }^{6}[. .$.$] atitude em relação à linguagem e seu uso se torna especialmente atraente quando vista na sua verdadeira$ magnitude o fato de que as línguas não são apenas portadoras de formas e atributos linguísticos determinados, mas também são capazes de transmitir significados ou conotações sociais, bem como valores sentimentais. As regras e as marcas culturais de um grupo se transmitem ou se destacam por meio da língua (MORENO FERNÁNDEZ, 1998, p. 178 - tradução do autor).
} 
Dossiê: Atitudes Linguísticas e Políticas Linguísticas: abordagens interdisciplinares

Já a atitude linguística, segundo Aguilera (2008, p. 106) "é o resultado da soma de suas crenças, conhecimentos, afetos e tendências a comportar-se de uma forma determinada diante de uma língua ou de uma situação sociolinguística". Dessa maneira, as crenças e atitudes estão interligadas e se conectam aos conceitos estabelecidos por grupos sociais de falantes.

Nessa perspectiva, Haugen (1956, p. 118) observa que em situações onde há contato, existe a prevalência de certas atitudes, favoráveis ou desfavoráveis, quanto às línguas envolvidas. Isto está calcado em julgamentos e estereótipos intergrupais, atribuídos aos falantes e às suas línguas. Posteriormente, Romaine (1995, p. 290) considerou as formas ajuizadoras com relação às línguas, como mediadoras e determinadoras das relações entre os grupos. Esses estudos nos mostram que as atitudes linguísticas funcionam como termômetros na avaliação da vitalidade de uma língua, em especial das minoritárias, processo que está associado aos aspectos sociais.

As teorias abordadas confirmam a abordagem dos dados analisados até o momento, quanto aos espaços de circulação de práticas linguísticas no jornal em voga, em que, de forma intencional, o jopará é relegado às páginas de maior apelo popular, o que demonstra ser uma ação proveniente do planejamento incidente sobre as funções atribuídas a cada língua, em um ambiente marcado pelo contato linguístico, em que se deflagra a intervenção do Estado, corroborada pelo domínio linguístico de grupos sociais influentes, podendo afetar a forma como as pessoas reagem a esta temática.

O jopará, em tal ambiente, por tais motivos, pode sofrer alguma desaprovação ou negação, baseadas em crenças, hábitos e atitudes. Trato, a seguir, de aprofundar essa premissa, por meio da exposição de algumas reflexões; para tanto, sob essa ótica, revitalizo os resultados de outro estudo concernente ao tema.

\section{AS ATITUDES LINGUíSTICAS QUANTO AO JOPARÁ NAS PÁGINAS POLICIAIS DO DIÁRIO POPULAR}

Nesta fase da investigação, recorro aos dados $\operatorname{coletados}^{7}$ pela aplicação de um questionário a 50 respondentes, funcionários do comércio de Ciudad del Este, Paraguai,

\footnotetext{
${ }^{7}$ Projeto avaliado e aprovado pelo Comitê de Ética em Pesquisa da UNIOESTE. Parecer no. 2.676.585.
} 
Dossiê: Atitudes Linguísticas e Políticas Linguísticas: abordagens interdisciplinares

provenientes de minha pesquisa de doutorado (SANTOS, 2019), que analisei o tema sob outro viés. Um recorte foi necessário para a formação do corpus desta etapa do presente estudo, tendo em vista o que se almeja.

O questionário aplicado era composto de sete questões fechadas, estilo múltipla escolha, acrescidas de duas abertas, pelas quais era possível expressar opinião de forma escrita. Deste total, selecionei somente três fechadas e uma aberta.

O corpus abarca os resultados das questões fechadas, pelas quais busquei, de maneira numérica, com foco no caráter subjetivo, evidenciar o grau de aceitação das matérias redigidas em jopará, assim como comprovar se haveria maior ou menor aprovação, caso a equipe editorial do jornal em foco optasse pela redação monolíngue: castelhano ou guarani.

Também é composto pelo resultado de uma questão aberta, que apurou de forma mais direta os julgamentos concernentes ao jopará no contexto analisado, tendo em vista o propósito da corrente pesquisa, que busca, segundo Aguilera (2008), apurar as respostas subjetivas diante de uma língua ou variação, tendo como premissa a interconexão entre os posicionamentos, o efeito do planejamento linguístico e o condicionamento de seu uso a um determinado segmento, no caso o informal, popular.

Os participantes são homens e mulheres, maiores de 18 anos, residentes em Ciudad del Este, município de Alto Paraná, no Paraguai, que manifestaram ler e conhecer o Diario Popular.

Dos 50 respondentes, 32 são do sexo masculino e 18 do feminino. A abordagem foi feita sem orientação quanto ao sexo ou escolaridade, calhando de serem preponderantes os homens. Quanto a estes dados, para a finalidade da análise, somente é considerada a variante relativa à escolaridade.

Quanto à escolaridade, foram empregados os níveis, segundo a composição do sistema escolar paraguaio, cujos resultados foram: 02 com ensino primário incompleto; 05 com ensino primário completo; 05 com educação media incompleta; 13 com educação média completa; 14 com ensino superior incompleto; 09 com ensino superior completo e 02 respondentes não informaram. $O$ ato de aplicar o instrumento forneceu dados e experiências.

Os respondentes, em muitos casos, quando informados sobre o tema do questionário, demostraram estranhamento e em algumas situações acharam graça. Essas dúvidas e risos sinalizaram a possível formação de um julgamento com relação ao tema de pesquisado, pois, 
Dossiê: Atitudes Linguísticas e Políticas Linguísticas: abordagens interdisciplinares

como já apuramos, quanto ao periódico, fruto do seu enquadramento no segmento popular, as escolhas editoriais, que incluem a escrita em jopará, incorrem em estigmatizações, tais como: jornal não sério, linguagem popular. Tais formas de pensar/reagir são decorrentes, possivelmente, de julgamentos fundados pela forma como o Popular projeta o universo linguístico dos leitores amparados pelas relações de interação social e o contexto informal de uso relegado ao jopará (GARRETT, 2010).

Quanto aos resultados obtidos, referentes à questão em que os participantes deveriam escolher uma alternativa que expressasse sua opinião relativa às matérias redigidas em jopará, 27 respondentes optaram pela alternativa que indica um grau alto de aceitação, isso assinala, em termos percentuais, um total de $54 \%$, ou seja, mais da metade. O nível baixo de aceitação quanto a este tema foi de $6 \%$.

Segundo as variações relativas à escolaridade dos participantes, pertinente a esta inquirição, nota-se que a maioria, entre os que se mostram favoráveis ao jopará no contexto em questão, tem o ensino de nível médio completo. Já a maioria dos que possuem nível superior completo gostam, medianamente, de ler as notícias em jopará.

Refletindo sobre tais resultados, com base no aporte teórico de Bourdieu (2014), observo que os órgãos de imprensa e outras instituições paraguaias, tais como o sistema escolar, têm suas práticas permeadas por uma ideologia, que encaminha ao afunilamento cultural, unilateral, na forma como os gostos, as crenças e os valores, oriundos de grupos sociais dominantes, são base para a distinção. Não obstante, segundo já apurei, conforme Calvet (2007), tais números podem ser reflexo do planejamento linguístico, ancorado pela criação de leis, aplicáveis a todo contexto formal de uso. Nessa ordem, segundo Aguilera (2008), as atitudes favoráveis ou de rejeição às línguas e variantes são reguladas por grupos sociais detentores de maior prestígio.

Nesse âmbito, os entrevistados cujos níveis escolares são mais avançados são os que revelam atitude negativa, em nível mediano, quanto ao jopará no contexto investigado. Essa forma de julgamento, apurada pelo resultado das respostas, pode ser decorrente da interiorização de um esquema de percepções e categorizações, que no meio escolar paraguaio, caracterizado pelo contato linguístico, garante status de língua ao guarani e ao castelhano, segundo sua "pureza" (BOURDIEU, 2009).

Contudo, é necessário observar que o nível mais alto de rejeição à redação em jopará 
Dossiê: Atitudes Linguísticas e Políticas Linguísticas: abordagens interdisciplinares

é de apenas $6 \%$. Os entrevistados, segundo suas respostas referentes à questão fechada que pretendia apurar se os respondentes desejariam o impresso editado em língua única, guarani ou castelhano, indicaram majoritariamente que não o querem dessa forma.

Do total da amostra, $60 \%$ não estão de acordo com a redação em língua castelhana e $70 \%$ não a querem em língua guarani padronizada. Esses dados, com base em Moreno Fernández (1998), podem denotar a crença dos entrevistados quanto à aceitação e delimitação de circulação do jopará a um ambiente que remete à informalidade e que o reconhece como pertencente ao universo cultural de uma parte da população, visto que, intencionalmente, pelo trabalho editorial, o Popular veicula a construção de sua imagem, por meio da linguagem, a um perfil de leitor que, em virtude das respostas fornecidas, vê-se projetado no jornal.

A atitude desfavorável ao uso de língua "pura", guarani ou castelhana, nos moldes apontados por essa pesquisa, não descredita o resultado proveniente da gestão de línguas, in vitro, ocorrida no Paraguai. Com base em Calvet (2007), este tipo de planejamento linguístico, marcado pela criação de leis, consolidou o castelhano como língua dominante, língua formal, e acolheu o guarani padrão como símbolo nacional.

Contudo, os dados que demonstram negação acentuada ao emprego dessas línguas no Diario Popular, podem conectá-la ao pouco domínio, especialmente do guarani normalizado, na modalidade escrita, visto que, segundo Gasparin (2016), essa competência linguística pode ser algo idealizado, somente alcançada por uma parcela pequena da população, fruto também de um sistema de ensino ainda precário.

Com base em Melià (1997), os dados apurados me permitem refletir que as práticas linguísticas no Paraguai ocorrem em virtude de sua constituição, enquanto expressão de uma cultura plural, no entanto, pela interferência do Estado ou pela imposição do modus vivendi de grupos e classes sociais dominantes, remanescentes desde o período colonial, percebe-se que, neste ambiente, cada língua ou variação tem seu lugar.

O jopará, por ser forma de expressão espontânea da população ou empregado quando se deseja ser amigável e confiável, para fazer-se entender e aceitar em ambientes informais (ZAJíCOVÁ, 2009), embora não tenha capital simbólico para ultrapassar seus limites de circulação, acaba por converter-se, segundo Krivoshein de Canese (1996), em um problema a ser sanado pela educação formal, visto que, escapa ao controle do planejamento linguístico e "atrapalha" a idealizada regularização das línguas oficiais. 
Dossiê: Atitudes Linguísticas e Políticas Linguísticas: abordagens interdisciplinares

No entanto, os dados que uso para a presente pesquisa apontam que $60 \%$ dos informantes gostam muito de redações em jopará nas páginas policiais. Esse dado pode estar de acordo com as concepções quanto ao estilo do jornal, que o acercam ao estereótipo sensacionalista, pouco formal, compatível ao uso do jopará, atrelado à coloquialidade.

Concernente a essa informação, segundo respostas abertas, os participantes revelaram atitudes relativas à questão sobre o sentimento quanto às palavras de origem guarani, em língua jopará, nas páginas policiais:

[...] le gusta a la gente (as pessoas gostam- tradução nossa -respondente 03; SANTOS, 2019)

Estira mas leer el diario (Da mais vontade de ler- tradução nossa respondente 04; SANTOS, 2019)

Se expresa bien y da a entender en lenguaje popular (Expressa-se bem e da para entender a linguagem popular - tradução nossa - respondente 06; SANTOS, 2019)

[...] el jopara es lo que los paraguayos más usamos casi todos, o sea los de la clase media, baja en la mayoría y por ello las personas entienden mejor (o jopará é o que os paraguaios mais usamos quase todos, na maioria e por ele as pessoas se entendem melhor - tradução nossa - respondente 19; SANTOS, 2019)

El jopara es la lengua oficial de manera que debería de ser realizada de la misma manera que otras lenguas y no solo propiciar una, ya que personas no tienen tanto conocimiento del español (O jopará é uma língua oficial de forma que deveria ser realizada da mesma maneira que outras línguas e não somente propiciar uma, já que pessoas não têm tanto conhecimento do español - tradução nossa - respondente 21; SANTOS, 2019)

Me gusta porque los paraguayos no tienen que negar su idioma (Eu gosto porque os paraguaios não têm que negar seu idioma - tradução nossa respondente 22; SANTOS, 2019)

Os respondentes 03, 06 e 21 confirmam em suas respostas um fator já arrolado, baseado no estudo de Patiño (2013), o baixo domínio da competência linguística em leitura, em castelhano padrão e guarani padrão. 0 respondente 06 expressa sua crença no jopará enquanto linguagem popular, que possibilita a comunicação. O respondente 19 corrobora com essa concepção e reconhece seu uso rotineiro. Os respondentes 21 e 22 entendem o jopará como idioma, contudo, por demonstrarem consciência da existência da padronização do castelhano e do guarani, não o concebem no mesmo nível das línguas oficiais. Tais resultados 
Dossiê: Atitudes Linguísticas e Políticas Linguísticas: abordagens interdisciplinares

demonstram atitudes positivas quanto ao jopará no contexto em questão.

Quanto aos dados analisados, decorrem, entretanto, atitudes negativas que, assim como as positivas, podem estar conectadas ao trabalho de sustentação, consolidação e legitimação das línguas oficiais padronizadas no Paraguai. Percebemos essa constatação também pelas respostas relacionadas à questão:

Porque se supone que es un diario serio, creo que las palabras se deben utilizar correctamente y no vulgarmente (Porque se supõe que é um diário sério, creio que as palavras devem ser utilizadas corretamente e não vulgarmente - tradução nossa - respondente 1; SANTOS, 2019)

Le quita un poco el carácter serio a la noticia (Tira um pouco o caráter sério da notícia - tradução nossa - respondente 10; SANTOS, 2019)

Leo y entiendo, pero no me gusta mucho el idioma guarani (Leio e entendo, mas não gosto muito do idioma guarani.- tradução nossa - respondente 18; SANTOS, 2019)

No estoy en contra del idioma guarani pero el diario utiliza términos muy vulgares. Nada mas por eso (ej. Yiyi) para nada me gusta (Não estou contra o idioma guarani mas o Diario utiliza termos muito vulgares. Nada além disso (ex. Yiyi)- tradução nossa - respondente 20; SANTOS, 2019)

Proveniente da possível consciência, relativa ao prestígio da estandardização linguística, estruturada e estruturante, as resposta 1 e 10 desvelam atitude negativa frente ao uso do jopará, pois, segundo seus respondentes, ele não é aceitável em um órgão de imprensa, visto que é avaliado como incorreto, vulgar, não pertencente ao corpo de atividades que envolvem o uso protocolar da linguagem.

Segundo o que indica o respondente 18, é possível alinhar sua crença a dois aspectos já tratados: a confirmação dos dados do Senso Populacional, que apontam a supremacia bilíngue e a potencial atitude negativa em relação à língua guarani, fruto da construção coletiva que associa o espectro da língua a pouca prosperidade econômica e social, que, apesar de mitigada por políticas que buscaram subverter essa consciência, todavia, segundo Patiño (2013), é uma forma de pensar que se acentua, sobretudo, entre a população dos centros urbanos.

O respondente 20 compreende que o jornal emprega uma variação do guarani, 
Dossiê: Atitudes Linguísticas e Políticas Linguísticas: abordagens interdisciplinares

reconhecendo-o como idioma, não manifestando conceito negativo, mas sim contra o jornal e o estilo de linguagem empregado. O termo que a resposta destaca como vulgar (yiyi) é um neologismo que qualifica a mulher pela aparência física, algo que escapa ao controle da língua, portanto é conceituado como inapropriado a um órgão de imprensa. Suas reações, segundo Bourdieu (1989), podem estar estruturadas na forma de agir, pensar e classificar, baseadas por hábitos cultivados por grupos de prestígio, tais como o emprego de uma linguagem sóbria em situações formais, que no Paraguai indicam o uso do castelhano padrão, monolíngue, como expressão adequada. As atitudes negativas quanto ao jopará no contexto investigado, segundo Labov (1987), podem ser decorrentes dos julgamentos que vinculam essa forma de expressão a grupos sociais paraguaios com menor prestígio e incompatibilizam seu emprego aos fatos da vida pública, formal.

\section{CONSIDERAÇÕES FINAIS}

Os dados provenientes de outros trabalhos sobre o tema, reempregados no corrente estudo, permitiram-me apresentar algumas reflexões concernentes às atitudes linguísticas em relação ao jopará no Diário Popular. A essas, acrescento as derradeiras, como forma de sintetizar minhas ponderações.

No presente estudo, observo que tanto o processo de formação histórico, quanto a intervenção do Estado e o prestígio de grupos sociais no Paraguai incidem sobre gestão das línguas, constatação que pode confirmar a visão sobre a língua e linguagem, não restrita a atos de comunicação independentes, mas atrelada ao campo das relações sociais.

As análises apontam que as classificações, conceitos e opiniões, provenientes dos dados gerados pela aplicação do questionário, são formulados segundo esquema, interiorizado, estruturado e estruturante, associado ao grau de escolarização. Tal esquema rege as formas de pensar, agir e avaliar (ações, pessoas, coisas, línguas, variações), em que, pertinente aos aspectos linguísticos atrelados às esferas sociais dominantes, considera-se legítimo o uso das formas padronizadas de guarani e castelhano e aceitável o jopará, enquanto expressão da cultura popular, condicionado a contextos informais.

\section{REFERÊNCIAS}


AGUILERA, V.A. Crenças e atitudes lingüísticas: o que dizem os falantes das capitais brasileiras. Estudos Lingüísticos, São Paulo, v. 37, n. 2, 2008, p. 105-112.

AMARAL, M. F. Jornalismo Popular. São Paulo: Contexto, 2005.

BOURDIEU, P.. O poder simbólico. Lisboa: DIFEL, 1989.

BOURDIEU, P. A economia das trocas linguísticas. São Paulo: Edusp, 1996.

BOURDIEU, P. A economia das trocas simbólicas. São Paulo: Perspectiva, 2009.

BOURDIEU, P.; PASSERON, J. C. A reprodução: elementos para uma teoria do sistema de ensino. Petrópolis: Vozes, 2014.

CALVET, L. J. As Políticas Linguísticas. São Paulo: Parábola, 2007.

CHIAVENATO, J. J. Genocídio americano: a guerra do Paraguai. São Paulo: Brasiliense, 1979.

CORVALÁN, G. Educación bilingüe bicultural. Nemity. Asunción, n 26, ene/jun, 1993, p.p. 1924.

GARRETT, P. Attitudes to language. Cambridge: Cambridge University Press, 2010.

GASPARÍN, M. N. Políticas linguísticas e representação de identidades: um estudo etnográfico em uma comunidade plurilíngue/pluricultural no Paraguai. Dissertação (Mestrado em Sociedade, Cultura e Fronteiras) - Universidade Estadual do Oeste do Paraná, 2016.

HAUGEN, E. Bilingualism in the Americas: a bibliography and research guide. Montgomery: University of Alabama Press, 1956.

KALLFELL, G. ¿Cómo hablan los paraguayos con dos lenguas? Gramática del jopara. 2016. Disponível em: <http:// www.etnolinguistica.org/biblio:kallfell-2016-jopara >. Acesso em: 15 jan. 2020.

KRIVOSHEIN DE CANESE, N. Apuntes de lingüística general y aplicada. Assunção, 1996.

LABOV, W. The logic of nonstander English. In: LABOV, W. Language in the inner city: studies in the black English vernacular. Philadelphia: University of Pennsylvania Press, 1978.

LAMBERT, W.; LAMBERT, W.E. Psicologia Social. Rio de Janeiro: Zahar Editores, 1966.

LOPES, N. S. Concordância Nominal, Contexto Linguístico e Sociedade. (Tese de Doutorado), Universidade Federal da Bahia, Salvador, 2001. 
LUSTIG, W. Mba'eichapa oiko la guarani? Guaraní y jopara en el Paraguay. Disponível em: <http://www.etnolinguistica.org/artigo:lusting-1996>. Acesso em: 23 dez. 2019.

MELIÀ, B. La lengua Guarani Del Paraguay; Historia, sociedad y Literatura. Madrid, España, Ed. Mafre, 1992.

MELIÀ, B. El Guaraní conquistado y reducido. Asunción: CEADUC, 1997.

MELIÀ, B. Una nación dos culturas. Asunción: Salesiana, 1998.

MÉNDEZ, E. N. Minorías lingüísticas y derecho a las lenguas. Univ. Autónoma de Barcelona, 2013.

MORENO FERNÁNDEZ, F.. Principios de sociolingüística y sociología del lenguaje. Barcelona: Ariel, 1998.

PARAGUAY. 2003. II Censo Nacional Indígena de Población y Viviendas 2002. Pueblos Indígenas del Paraguay. Resultados finales. Fernando de la Mora: Dgeecpublicaciones, 2003.

PATIÑO, M. Actitudes Lingüísticas hacia la lengua guaraní de los estudiantes del segundo curso, turno noche, del nivel medio del Colegio Nacional Emr Dr Fernando de la Mora. Revista Paraguay desde las Ciencias Sociales, revista del Grupo de Estudios Sociales sobre Paraguay, ${ }^{\circ}$ 3, 2013, 41-60. Disponível em: http://www.grupoparaguay.org/revista>. Acesso em: 10 abril. 2020.

RODRÍGUEZ ZUCCOLILLO, C. M. Língua, nação e nacionalismo: um estudo sobre o guarani no Paraguai. Tese de Doutorado, Universidade Estadual de Campinas, São Paulo: 2000.

ROMAINE, S. Bilingualism. Oxford, Cambridge: Blackwell, 1995.

SANTOS, L. M. Ñande rekó/nosso modo de ser: o jopara no jornal Diario Popular. Dissertação (Mestrado em Sociedade, Cultura e Fronteiras) - Universidade Estadual do Oeste do Paraná, 2012.

SANTOS, L. M. O processo de construção do ethos do jornal Diario Popular. A imagem de si e do outro no discurso. Uma análise do jopará nas páginas policiais. Tese (Doutorado em Sociedade, Cultura e Fronteiras) - Universidade Estadual do Oeste do Paraná, 2019.

SERRA, A. O desvio nosso de cada dia: a representação do cotidiano num jornal popular. Rio de Janeiro: Achiamé, 1980.

ZAJíCOVÁ, L. Diferentes formas del jopara. In: Escobar, A. M. e Wölck, W. (org.) Contacto lingüístico y la emergencia de variantes y variedades lingüísticas. Madrid: VervuertIberoamericana, 2009, p.p 23-38. 
Recebido em 25 de junho de 2020.

Aprovado em 12 de novembro de 2020

(c) $(1)(0$

BY NC SA 